\title{
Lymfødem etter kreft - årsak, forekomst og behandling
}

Lymfødem er en lite anerkjent seneffekt etter kreftbehandling. Screening for lymfødem bør være en del av standard oppfølging av pasienter i risikogruppen.

\section{Forfatter}

Forfatter

Åse Sagen

lymfødem $\quad$ ødemer $\quad$ Kreft

Sykepleien 2018 106(72051)(e-72051)

DOI: https://doi.org/10.4220/Sykepleiens.2018.72051

\section{Hovedbudskap}

Forekomsten av lymfødem er økende, i takt med økningen i antallet krefttilfeller i befolkningen. Tilstanden utgjør en betydelig plage og reduserer livskvaliteten til dem som rammes.

Tidlig behandling og individuell oppfølging er av stor betydning for å unngå volumøkning, infeksjoner og ytterligere eskalering av tilstanden.

Lymfødem er en kronisk hevelse forårsaket av overbelastning av lymfesystemet eller nedsatt transportkapasitet for lymfevæske (1). Lymfeåresystemet er en viktig transportåre for spredning av kreftceller. Derfor er kirurgisk fjerning av lymfeknuter for å diagnostisere eller fjerne metastaser standard prosedyre ved en rekke kreftdiagnoser. Slike inngrep svekker lymfetransportkapasiteten og kan føre til lymfødem. 
Økningen i antallet krefttilfeller og andelen kreftoverlevere fører til at pasientgruppen med kreftrelatert lymfødem stadig vokser (2). Det finnes i dag ingen helbredende behandling for lymfødem. Livslang lymfødembehandling er derfor nødvendig.

\section{Redusert livskvalitet}

Lymfødem oppstår i ekstremitetene og på brystkassen, i ansiktet, halsen, på de ytre kjønnsorganer, ryggen eller magen. Målet for behandlingen er å redusere lymfødemet mest mulig og sammen med pasienten holde lymfødemet i sjakk for å unngå eskalering av tilstanden.

Lymfødem kan være svært plagsomt og kan føre til redusert livskvalitet (3), mentalt stress og redusert fysisk funksjon (4). Lymfødem kan føre til akutte hudinfeksjoner, erysipelas, også kalt sekundær akutt infeksjon (SAI) eller rosen, hvor symptomene er rød og varm hud, sykdomsfølelse og høy feber $(5,6)$.

\section{Lite anerkjent problem}

Tilstanden har en tendens til stadig å komme tilbake etter første anfall og medfører ofte sykehusinnleggelser (7). Anfallene eskalerer lymfødemet, og slik kommer pasienten inn i en negativ sykdomsspiral $(5,6)$. Tilstanden skal raskest mulig behandles med penicillin $(5,7)$.

Det er ikke kartlagt hvor mange sykehusinnleggelser som skyldes lymfødem med akutte hudinfeksjoner i Norge, og problemet er lite anerkjent $(5,7)$. Pasienter som er operert for kreft med risiko for å utvikle lymfødem, bør få informasjon om symptomer på lymfødem som en del av pasientforløpet for kreft $(8,9)$. Lymfødemscreening bør være en del av standard oppfølging fordi tidlig identifisering og rask behandling kan forhindre eskalering av lymfødemet $(8,9)$.

\section{三 «Tidlig identifisering og rask behandling kan forhindre eskalering av lymfødemet.»}

Fysioterapeuter og sykepleiere møter disse pasientene i både spesialist- og primærhelsetjenesten i ulike faser av sykdommen. Lymfødem bør behandles av fysioterapeuter med spesialkompetanse.

\section{Årsaker}


Kirurgisk fjerning av lymfeknuter for å diagnostisere eller fjerne metastaser er standard prosedyre ved en rekke kreftdiagnoser (brystkreft, tykktarms- og endetarmskreft, gynekologisk kreft, prostatakreft med flere) og er den viktigste årsaken til lymfødem etter kreftbehandling.

\section{$\equiv$ «Kreftspredning og innvekst av tumor i lymfeknutene kan føre til lymfødem.»}

Stråleterapi og overvekt (BMI > 25) i tillegg til lymfeknutekirurgi øker faren for å utvikle lymfødem ytterliger (10-12). Genetiske disposisjoner for å utvikle lymfødem er identifisert hos brystkreftpasienter $(2,13)$. Kreftspredning og innvekst av tumor i lymfeknutene kan føre til lymfødem. Ved utbredt metastasering kan det være flere faktorer som bidrar til sirkulasjonsforstyrrelser og ødemer.

\section{Forekomst}

Det finnes ikke et nasjonalt register for lymfødem i Norge og følgelig ikke eksakte tall for forekomsten av lymfødem, verken for medfødte lymfødem eller som følge av kreftbehandling. Vi har imidlertid sikre tall for brystkreft, hvor prevalensen av lymfødem i armen er 15 til 20 prosent etter armhuledisseksjon og mellom 2 og 5 prosent etter vaktpostlymfeknutekirurgi $(10,11)$.

Det finnes foreløpig ikke en sikker oversikt over prevalensen av lymfødem i underekstremitetene som følge av lymfeknutekirurgi i lyske og bekken, men basert på tilgjengelig internasjonal litteratur er forekomsten trolig mellom 30 og 40 prosent etter gynekologisk kreft (14-16). Forekomsten etter kreft i skjoldbruskkjertelen, øre-nese-halskreft og sarkom er lite kartlagt.

Det fjernes også lymfeknuter i bekkenet ved tykktarms- og endetarmskreft, men lymfødemforekomsten er lite kartlagt også her. Behandling for spredning ved føflekkreft innebærer ofte omfattende lymfedisseksjon i lyske eller armhule, og en forekomst på 31 prosent (arm) og 40 prosent (ben) er rapportert (3).

\section{Undersøkelse}


Korrekt og hurtig diagnose, samt differensialdiagnostisering for å utelukke andre sykdommer, er en forutsetning for riktig behandling. Hevelse i arm eller ben etter kreftbehandling kan også skyldes dyp venetrombose, spredning med innvekst i lymfeknuter i armhulen eller lyske, arteriell insuffisiens, hjertesvikt, infeksjoner og eventuelt andre sykdommer.

Ved diagnostisering og kartlegging av lymfødem følger man følgende prosedyre (1):

- innhente relevant informasjon for vurdering av diagnose og årsaksforhold: kirurgi, tidligere eller annen kreftbehandling, spredning, familiær historie

- vurdere differensialdiagnoser: dyp venetrombose (DVT), arteriell insuffisiens, hjertesvikt, infeksjoner og eventuelt andre sykdommer som kan forårsake hevelse

- kartlegge hevelse: debuttidspunkt, lokalisasjon, omkretsmål på definerte målepunkter ved lymfødem i ekstremiteter. På andre områder brukes et måleinstrument, en såkalt kaliper

- kartlegge symptomer som sprengfølelse, smerter, ubehag og tyngdefølelse

- palpasjon og inspeksjon av vev: hudkvalitet, elastisitet, tykkelse og hardhet

Testen Stemmers tegn er positiv på lymfødem dersom huden på dorsalsiden av grunnleddet på fingre og tær i det affiserte området kan løftes opp med to fingre. Testen Pitting gir en indikasjon på begynnende lymfødem dersom det blir stående et søkk etter et lett trykk med en finger. Et etablert lymfødem vil vanligvis ikke ha utslag på denne testen.

LYMFQOL er et validert spørreskjema for fysisk funksjon og livskvalitet hos pasienter med lymfødem. Skjemaet finnes for både over- og underekstremiteter, er oversatt til norsk og fås gratis på fysio.no (https://fysio.no/Forbundsforsiden/Organisa sjon/Faggrupper/Onkologi-og-lymfologi/Kliniske-maaleinstru

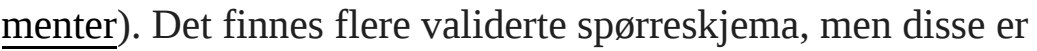
ikke oversatt til norsk.

\section{Behandling}


Pasienter med lymfødem må ha livslang behandling for å holde ødemet i sjakk for å unngå forverring av tilstanden. En brukerstyrt plan for oppfølging og vedlikehold er viktig for å holde pasientenes motivasjon oppe i tillegg til å sikre en god og trygg behandling.

Komplett fysikalsk lymfødembehandling (KFL) er en anerkjent behandlingsform som består av kompresjonsbehandling (bandasjering og kompresjonsplagg), manuell lymfedrenasje, sirkulasjonsfremmende øvelser, hudpleie og informasjon om egenbehandling. Behandlingen reduserer ødemene og lindrer symptomene. KFL utføres i Norge av fysioterapeuter med spesialkompetanse.

\section{三 «Pasienter med lymfødem må ha livslang behandling.»}

Metoden er anbefalt av det internasjonale Lymfologiforbundet og International Lymphoedema Framework for behandling av lymfødem (1). Ødemer som får stå ubehandlet over tid, kan være vanskelige å behandle fordi lymfødemet vil omdannes til fett med fibrosedannelser i underhuden, noe som medfører at ødemet responderer dårligere på behandling (2). Igangsetting av behandling og oppfølging tidlig etter diagnostisering er derfor viktig for å få kontroll med sykdomsutviklingen.

\section{Kompresjonsbehandling}

Kompresjonsbehandling med kortelastiske bandasjer og tilpasning av kompresjonsstrømper har god effekt med hensyn til å redusere lymfødem i ekstremitetene (17). Grad av kompresjon er avgjørende for vellykket behandling og reguleres med hvor stramt bandasjen legges, og antallet lag med bandasje.

Det vil være store individuelle forskjeller i tålegrad og effekt av kompresjonsbehandlingen. Imidlertid er det få studier på hvor stramt og hvor lenge kompresjonen skal sitte. Individuell tilpasning og klinisk erfaring er derfor nødvendig. Det er ulike kompresjonsklasser på kompresjonsmateriell som for eksempel strømper og hansker $(1-4,17)$.

\section{«Grad av kompresjon er avgjørende for vellykket behandling.»}


Det er få studier for behandling av lymfødem i genitalia, men kompresjonsbukse (panty) har vist effekt (18). Det finnes også kompresjonsmaske til bruk ved lymfødem i ansikt, og klinisk erfaring viser at dette kan ha en betydelig positiv effekt på hevelse og medfølgende plager, eventuelt i kombinasjon med lymfedrenasje (19).

Pulsator massasjeapparat gir intermitterende mekanisk trykkbehandling for reduksjon av lymfødem. Klinisk erfaring viser effekt når det kombineres med kompresjonsplagg etter behandling (1). En metaanalyse fra 2014 kunne ikke vise at pulsator alene hadde effekt på brystkreftrelatert lymfødem (20).

Kinesiotape brukes ofte på kroppsdeler med lymfødem hvor det ikke kan brukes strømper, og ser ut til å ha en viss effekt, selv om forskningen foreløpig har noe motstridende resultater $(1,21)$.

\section{Manuell lymfedrenasje}

Klinisk erfaring viser at manuell lymfedrenasje kan dempe ubehag, spreng og smerte samt redusere fibrose, og er anerkjent praksis i forkant av bandasjering, spesielt i intensivfasen av lymfødembehandlingen (1). Manuell lymfedrenasje i kombinasjon med kompresjonsbukse (panty) har vist effekt for lymfødem i genitalia (18) samt en liten effekt i kombinasjon med kompresjonsbehandling for lymfødem i armen etter brystkreft (17).

Forskning viser foreløpig ikke effekt av manuell lymfedrenasje på reduksjon av store ødem og fibrotisering i armen etter brystkreft, men det kan ha effekt på små og moderate ødem $(22,23)$.

I områder med lymfødem er immunforsvaret redusert. Det er derfor viktig å forebygge hudinfeksjoner med god hygiene ved å holde huden ren og myk. Man bør unngå sprekker og sår som kan gi infeksjoner og forverring av lymfødemet (5, 24). Særlig hudhygiene for føttene er viktig å følge opp av helsepersonell fordi det kan være vanskelig for pasienten å stelle føttene selv.

\section{Sirkulasjonsfremmende øvelser}


Fysisk aktivitet, trening og sirkulasjonsøvelser har en positiv effekt på perifer og sentral sirkulasjon. Det fremmer venøs tilbakestrømming og lymfedrenasje og anbefales som en del av lymfødembehandlingen. Helsegevinsten er særlig stor for denne pasientgruppen fordi generell fysisk aktivitet og trening kan forhindre overvekt som forverrer lymfødemet. Kostholdsveiledning, trening og vektreduksjon kan gi signifikant reduksjon av lymfødemet $(17,25)$.

Stavgang har vist en direkte positiv effekt på lymfødem etter brystkreft (26). Det har tidligere vært antatt at det ikke bør utføres styrketrening med den affiserte ekstremiteten som har risiko for å få, eller har fått, lymfødem. Det er imidlertid kommet to metaanalyser som tyder på at lymfødemet heller reduseres enn økes ved trening, og at risikoen for å utvikle lymfødem reduseres etter brystkreftoperasjon $(27,28)$.

\section{三 «Stavgang har vist en direkte positiv effekt på lymfødem etter brystkreft.»}

Det er foreløpig få studier på trening for dem som har risiko for å få lymfødem i bena, men en tverrsnittsstudie med 213 livmorkreftpasienter rapporterte om reduksjon i benlymfødem hos dem som drev fysisk aktivitet og turgåing hver dag (29). En randomisert kontrollert studie fra 2017 viste at det var mest reduksjon i benlymfødemet med stor motstand på ergometersykkelen, i forhold til lite motstand, og i forhold til bare kompresjonsstrømpe uten trening (30).

Det anbefales uansett å tilpasse treningen individuelt, starte med lav til moderat belastning, for så å øke belastningen gradvis. For pasienter med lymfødem er det anbefalt at styrketrening utføres med kompresjonsplagg på (27). Tøyninger kan forebygge og bedre nedsatt bevegelighet i ledd som følge av lymfødem. Øvelser i vann har vist god effekt på skulderbevegelighet i en randomisert pilotstudie hos pasienter med lymfødem etter brystkreftbehandling (31).

\section{Referanser}

1. Consensus. The diagnosis and treatment of peripheral lymphedema: 2013 Consensus Document of the International Society of Lymphology. Lymphology. 2013;46(1):1-11. 
2. Mortimer PS, Rockson SG. New developments in clinical aspects of lymphatic disease. J Clin Invest. 2014;124(3):915-21.

3. Cromwell KD, Chiang YJ, Armer J, Heppner PP, Mungovan K, Ross MI, et al. Is surviving enough? Coping and impact on activities of daily living among melanoma patients with lymphoedema. European Journal of Cancer Care. 2015;24(5):724-33.

4. Chachaj A, Malyszczak K, Pyszel K, Lukas J, Tarkowski R, Pudelko M, et al. Physical and psychological impairments of women with upper limb lymphedema following breast cancer treatment. Psychooncology. 2010;19(3):299-305.

5. Moffatt CJ, Franks PJ, Doherty DC, Williams AF, Badger C, Jeffs E, et al. Lymphoedema: an underestimated health problem. QJM. 2003;96(10):731-8.

6. Ridner SH, Deng J, Fu MR, Radina E, Thiadens SR, Weiss J, et al. Symptom burden and infection occurrence among individuals with extremity lymphedema. Lymphology. 2012;45(3):113-23.

7. Inghammar M, Rasmussen M, Linder A. Recurrent erysipelas - risk factors and clinical presentation. BMC infectious diseases. 2014;14:270.

8. Shaitelman SF, Cromwell KD, Rasmussen JC, Stout NL, Armer JM, Lasinski BB, et al. Recent progress in the treatment and prevention of cancer-related lymphedema. CA Cancer J Clin. 2015;65(1):55-81.

9. Stout NL, Binkley JM, Schmitz KH, Andrews K, Hayes SC, Campbell KL, et al. A prospective surveillance model for rehabilitation for women with breast cancer. Cancer. 2012;118(8 Suppl):2191-200.

10. Disipio T, Rye S, Newman B, Hayes S. Incidence of unilateral arm lymphoedema after breast cancer: a systematic review and meta-analysis. Lancet Oncol. 2013;14(6):500-15. 
11. Sagen A, Kaaresen R, Sandvik L, Thune I, Risberg MA. Upper limb physical function and adverse effects after breast cancer surgery: a prospective 2.5-year follow-up study and preoperative measures. Arch Phys Med Rehabil. 2014;95(5):875-81.

12. Sagen A, Karesen R, Risberg MA. Physical activity for the affected limb and arm lymphedema after breast cancer surgery. A prospective, randomized controlled trial with two years follow-up. Acta Oncol. 2009;48(8):1102-10.

13. Stanton AW, Modi S, Mellor RH, Levick JR, Mortimer PS. Recent advances in breast cancer-related lymphedema of the arm: lymphatic pump failure and predisposing factors. Lymphat Res Biol. 2009;7(1):29-45.

14. Yost KJ, Cheville AL, Al-Hilli MM, Mariani A, Barrette BA, McGree ME, et al. Lymphedema after surgery for endometrial cancer: prevalence, risk factors, and quality of life. Obstet Gynecol. 2014;124(2 Pt 1):307-15.

15. Dunberger G, Lindquist H, Waldenstrom AC, Nyberg T, Steineck G, Avall-Lundqvist E. Lower limb lymphedema in gynecological cancer survivors - effect on daily life functioning. Support Care Cancer. 2013;21(11):3063-70.

16. Brown JC, Chu CS, Cheville AL, Schmitz KH. The prevalence of lymphedema symptoms among survivors of long-term cancer with or at risk for lower limb lymphedema. Am J Phys Med Rehabil. 2013;92(3):223-31.

17. McNeely ML, Peddle CJ, Yurick JL, Dayes IS, Mackey JR. Conservative and dietary interventions for cancer-related lymphedema: a systematic review and metaanalysis. Cancer. 2011;117(6):1136-48.

18. Liao SF, Huang MS, Chou YH, Wei TS. Successful complex decongestive physiotherapy for lymphedema and lymphocutaneous reflux of the female external genitalia after radiation therapy. J Formos Med Assoc. 2003;102(6):404-6.

19. Smith BG, Lewin JS. Lymphedema management in head and neck cancer. Curr Opin Otolaryngol Head Neck Surg. 2010;18(3):153-8. 
20. Shao Y, Qi K, Zhou QH, Zhong DS. Intermittent pneumatic compression pump for breast cancer-related lymphedema: a systematic review and meta-analysis of randomized controlled trials. Oncol Res Treat.

2014;37(4):170-4.

21. Bosman J. Lymphtaping for lymphoedema: an overview of the treatment and its uses. Br J Community Nurs. 2014;Suppl:S12, S4, S6-S, S4, S8.

22. Ezzo J, Manheimer E, McNeely ML, Howell DM, Weiss R, Johansson KI, et al. Manual lymphatic drainage for lymphedema following breast cancer treatment. The Cochrane database of systematic reviews. 2015;5:CD003475.

23. Javid SH, Anderson BO. Mounting evidence against complex decongestive therapy as a first-line treatment for early lymphedema. J Clin Oncol. 2013;31(30):3737-8.

24. Ridner SH, Murphy B, Deng J, Kidd N, Galford E, Bonner $\mathrm{C}$, et al. A randomized clinical trial comparing advanced pneumatic truncal, chest, and arm treatment to arm treatment only in self-care of arm lymphedema. Breast Cancer Res Treat. 2012;131(1):147-58.

25. Shaw C, Mortimer P, Judd PA. A randomized controlled trial of weight reduction as a treatment for breast cancer-related lymphedema. Cancer. 2007;110(8):1868-74.

26. Jonsson C, Johansson K. The effects of pole walking on arm lymphedema and cardiovascular fitness in women treated for breast cancer: a pilot and feasibility study. Physiotherapy theory and practice. 2014;30(4):236-42.

27. Cheema BS, Kilbreath SL, Fahey PP, Delaney GP, Atlantis E. Safety and efficacy of progressive resistance training in breast cancer: a systematic review and metaanalysis. Breast Cancer Res Treat. 2014;148(2):249-68.

28. Paramanandam VS, Roberts D. Weight training is not harmful for women with breast cancer-related lymphoedema: a systematic review. J Physiother. 2014;60(3):136-43. 
29. Brown JC, Lin LL, Segal S, Chu CS, Haggerty AE, Ko EM, et al. Physical activity, daily walking, and lower limb lymphedema associate with physical function among uterine cancer survivors. Support Care Cancer. 2014;22(11):3017-25.

30. Fukushima T, Tsuji T, Sano Y, Miyata C, Kamisako $\mathrm{M}$, Hohri $\mathrm{H}$, et al. Immediate effects of active exercise with compression therapy on lower-limb lymphedema. Support Care Cancer. 2017;25(8):2603-10.

31. Johansson K, Hayes S, Speck RM, Schmitz KH.

Water-based exercise for patients with chronic arm lymphedema: a randomized controlled pilot trial. Am J Phys Med Rehabil. 2013;92(4):312-9. 